\title{
Grain Size Dependence of Steady State Creep Rate in Sn-1 wt\% Zn Alloy
}

\author{
G.S. Al-Ganainy and M.T. Mostafa* \\ Department of Physics, Faculty of Science, \\ *Department of Physics, Faculty of Education, Ain Shams University, \\ Cairo, Egypt
}

The effect of grain size as well as ageing temperature on the steady state creep and microstructure parameters of Sn-1 wt\% Zn alloy have been studied. The steady state creep rate ${ }^{\prime} \mathcal{\varepsilon}_{s}$ is found to increase with ageing temperature, whereas it decreases by increasing grain size. The relation between ${ }^{\circ} \varepsilon_{s}$ and the ageing temperature was fitted by a computer program and was found to be expressed as $\ln { }^{\circ} \varepsilon_{s}=A+B T^{l}$ with a strong negative correlation coefficient $\approx-1$. The values of the activation energies controlling the creep process around the transformation temperature (423K) from $(\alpha+\beta)$ phases to $\beta$-phase were calculated. The variations of ${ }^{\circ} \varepsilon_{s}$ and the microstructure parameters $\left(a, c, \Delta a / a_{o}\right.$ and $\left.c / a\right)$ with the ageing temperature confirm the precipitation process of Zn-rich phase in the temperature range (393-413 K) and its dissolution in the temperature range $(413-423 \mathrm{~K})$. 


\section{Introduction}

The low mechanical strength of tin metal due to its high softness leads to the idea of strengthening it by hardening alloying element $[1,2]$. So, it was interesting for many workers to investigate the effect of adding alloying elements on the physical and mechanical properties of Sn metal.

The creep behaviour of the eutectic solder (91 Sn - $9 \mathrm{Zn}$ ) has been investigated [3]. The creep tests have been done in load-control with initial stresses in the range of 10-22 MPa at two temperatures, 25 and 80 degree $\mathrm{C}$. The activation energies obtained from the creep tests were discussed in the light of the governing mechanisms. The steady state creep of $\mathrm{Sn}-0.5 \mathrm{wt} \% \mathrm{Zn}$ and $\mathrm{Sn}-9 \mathrm{wt} \% \mathrm{Zn}$ alloys were investigated in the temperature range from 373 to $453 \mathrm{~K}$ [4]. The steady state creep in the low temperature range (below $413 \mathrm{~K}$ ) was found to be controlled by grain boundary diffusion while it was controlled by volume self-diffusion in the high temperature range [5]. The steady state creep and lattice parameters of Sn- $1 \mathrm{wt} \% \mathrm{Zn}$ alloy were determined around the transition temperature [2]. The steady state creep rate increased with increasing the working temperature with an anomalous behaviour in the vicinity of the transition temperature (423K). In the low temperature range (below 423K) cross slip creep occurred by overcoming the obstacles such as small precipitates which formed by the ageing process.

Heat treatment technique of alloys has a great effect on the resulting grain size. The influence of grain size on the activation energy of high temperature creep of some metals and alloys has been studied [6]. The activation energy of creep in both fine and coarse-grained specimens were determined and found to be equal to that of grain boundary diffusion and volume diffusion, respectively. The effect of grain diameter on the steady state creep rate of some alloys has been investigated $[7,8]$. The steady state creep rate was found to decrease with increasing the grain size and was related to it by a Petch style relation.

Because of the industrial important applications of Sn-1wt\%Zn alloy $[1,2]$ and the lack of information about the effect of grain diameter on its creep parameters, the aim of this work is to investigate:

i) The effect of grain size and ageing temperature on some steady state creep parameters.

ii) The determination of the structure parameters around the transformation temperature of this alloy.

A trial is made to get the best fitting and the best correlation among them.

\section{Samples and Experimental Procedure}

Appropriate amounts of $99.99 \% \mathrm{Sn}$ and $\mathrm{Zn}$ metals were used in preparing $\mathrm{Sn}-1 \mathrm{wt} \% \mathrm{Zn}$ alloy by vacuum melting. The ingot was homogenized by vacuum annealing at $403 \mathrm{~K}$ for 24 hours, then swaged in wire samples of diameter $1 \mathrm{~mm}$ and $10^{-2} \mathrm{~m}$ in length. The samples were divided into four groups. The groups were annealed at $473 \mathrm{~K}$, each group for a different time interval $(1 / 2,1,2$, and 3 hours) then rapidly quenched in water at room temperature $(293 \mathrm{~K})$. The heat treatment for different time intervals yielded 
groups of samples with grain diameters of 64, 80, 97 and $122 \mu \mathrm{m}$, respectively. The average grain diameter $l$ was measured by the line intercept method [9].

Strain-time relations were obtained using a conventional creep-testing machine with a length dial gauge of a sensitivity $10^{-4} \mathrm{~cm}$. All tensile creep tests were made under a constant applied stress $10.9 \mathrm{MPa}$ at constant temperatures ranging from 393 to $453 \mathrm{~K}$ with an accuracy of $\pm 1 \mathrm{~K}$.

The microstructures were examined before and after creep deformation of the group of samples with a grain diameter of $64 \mu \mathrm{m}$ rapidly quenched in cold water (293K) after creep tests. The diffraction patterns were obtained by using a Shimadzu X-ray diffractmeter (D-series (Japan)) with $\mathrm{CuK}_{\alpha}$ radiation and a nickel filter. The lattice parameters were calculated precisely using the leastsquares method computer program. A least squares method computer program gave the correlation coefficients and the fitting equations between the parameters.

\section{Experimental Results}

Isothermal creep curves of $\mathrm{Sn}$ $1 \mathrm{wt} \% \mathrm{Zn}$ alloy samples of different grain diameters 64, 80, 97 and $122 \mu \mathrm{m}$ were obtained under a constant stress of 10.9 $\mathrm{MPa}$ and at different working temperatures ranging from 393 to $453 \mathrm{~K}$ in steps of $10 \mathrm{~K}$ are shown in Fig.(1). All curves show only two stages, which are the steady state and the fracture stages $[2,10]$.

The values of the stationary creep rate ${ }^{\circ} \varepsilon_{\mathrm{s}}$ against the working temperatures for all the grain diameters are illustrated in Fig. 2. This figure shows that ${ }^{\circ} \varepsilon_{\mathrm{s}}$ decreases with increasing the grain diameter $l$ and increases with increasing the working temperature, and there is an anomalous behaviour in its variation around $423 \mathrm{~K}$.

The activation energies of the steady state creep $\mathrm{Q}_{\mathrm{s}}$ of $\mathrm{Sn}-1 \mathrm{wt} \% \mathrm{Zn}$ alloy are calculated from the slopes of the relation between $\ln { }^{\circ} \varepsilon_{\mathrm{s}}$ and $1 / \mathrm{T}$. Using the least squares method computer program

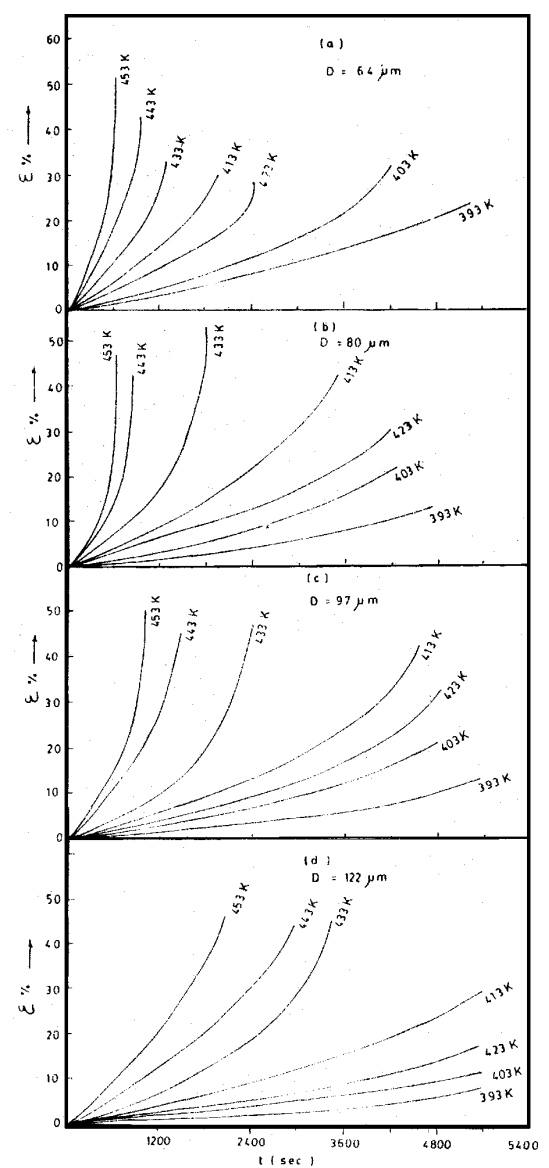

Fig. (1) Creep curves under a constant applied stress of $10.9 \mathrm{MPa}$ at different temperatures for $\mathrm{Sn}$ $1 \mathrm{wt} \% \mathrm{Zn}$ alloy and can be expressed as fits this relation 


$$
\ln \varepsilon_{\mathrm{s}}=\mathrm{A}+\mathrm{B} / \mathrm{T}
$$

with a strong negative correlation coefficient $\approx-1$ for all grain diameters in both the low (393$413 \mathrm{~K})$ and the high (423-453K) temperature ranges (Fig. 3). A and $\mathrm{B}$ are constants depending on the experimental conditions.

$\mathrm{Q}_{\mathrm{s}}$ is found to be slightly affected by the grain size and has average values of $(75.6 \pm 4.2)$ and $(103.1 \pm 3.8) \mathrm{kJ} / \mathrm{mol}$ in the low and high temperature regions, respectively.

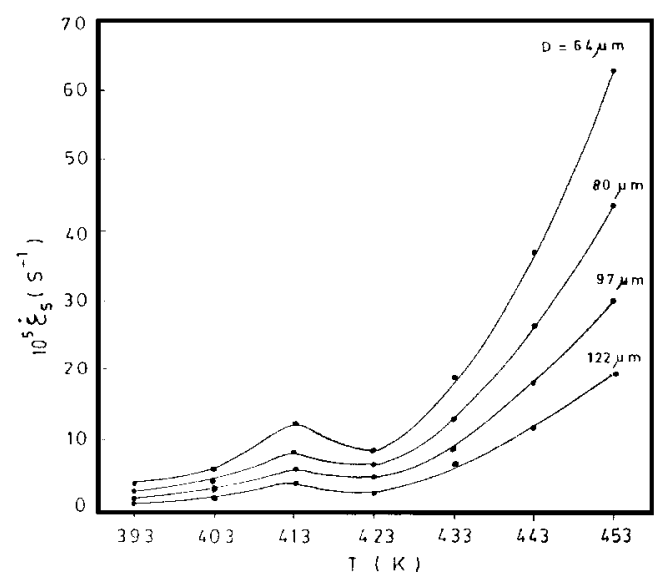

Fig. (2) Relation between ${ }^{\circ} \varepsilon_{s}$ and $T$ for different grain diameters.

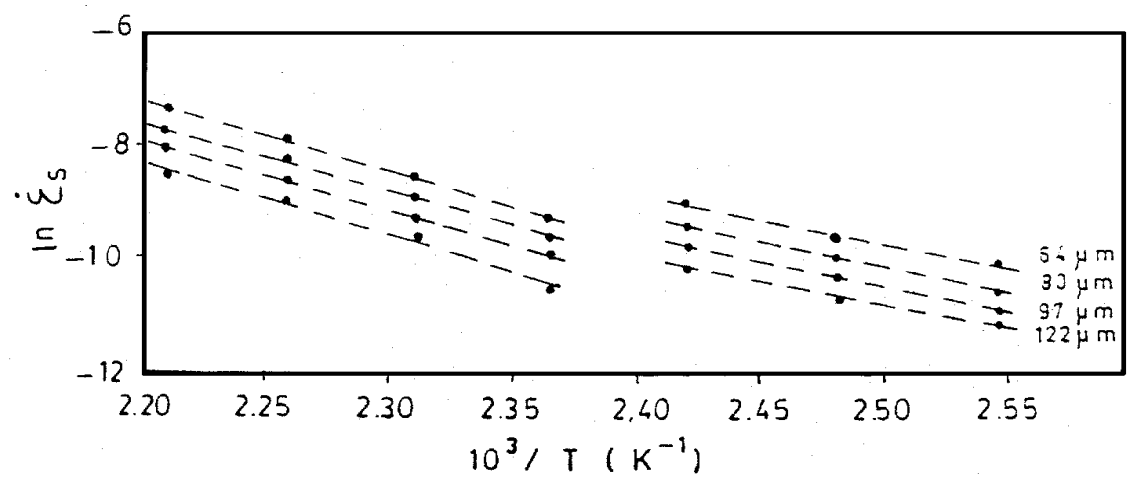

Fig. (3) Relation between $\ln { }^{\circ} \varepsilon_{\mathrm{s}}$ and $10^{3} / \mathrm{T}$ for different grain diameters, experimental values $(\bullet)$, calculated values from the best fitting equation $(----)$

The dependence of ${ }^{\circ} \varepsilon_{\mathrm{s}}$ on grain diameter $l$ for all specimens at different temperatures is shown in Fig. $4 \mathrm{a}$ from which it is clear that ${ }^{\circ} \varepsilon_{\mathrm{s}}$ decreases by increasing grain diameter. Figures 4 (b and c) show micrographs of rapidly quenched original samples after annealing at $473 \mathrm{~K}$ for 2 and $3 \mathrm{~h}$ respectively.

At each working temperature, the experimental values of both the steady state creep rate ${ }^{\circ} \varepsilon_{\mathrm{s}}$ and the reciprocal of the grain size $l^{-1}$ are fitted by a computer program (see Fig. 5). All these relations are found to be linear with a strong positive correlation coefficient $>0.98$ and satisfy an empirical relation of the form

$$
\dot{\varepsilon}_{\mathrm{s}}=\mathrm{a}+\mathrm{b} l^{-1}
$$

where $\mathrm{a}$ and $\mathrm{b}$ are constants depending on the experimental conditions. 
Fig. (4.a)

Relation between the grain diameter $l$ and ${ }^{\circ} \varepsilon_{\mathrm{s}}$ at different temperatures
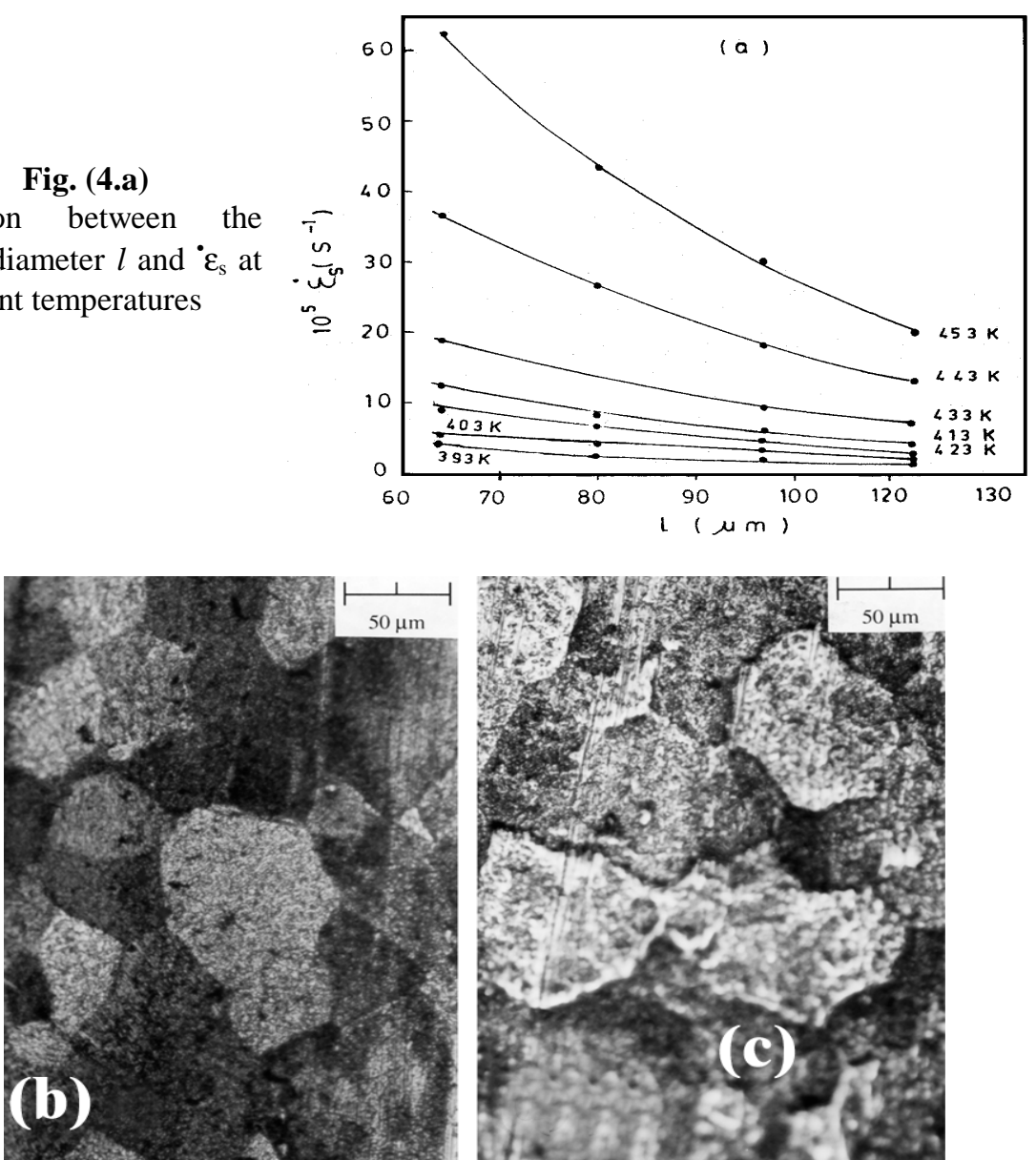

Fig. (4. B\&C) A micrograph of an original sample annealed at $473 \mathrm{~K}$ for 2 and $3 \mathrm{hrs}$.

Fig. (5)

Relation between ${ }^{\circ} \varepsilon_{\mathrm{s}}$ and the reciprocal of the grain diameter $l$ at different temperatures, experimental values $(\bullet)$, calculated values from the best fitting equations (----)

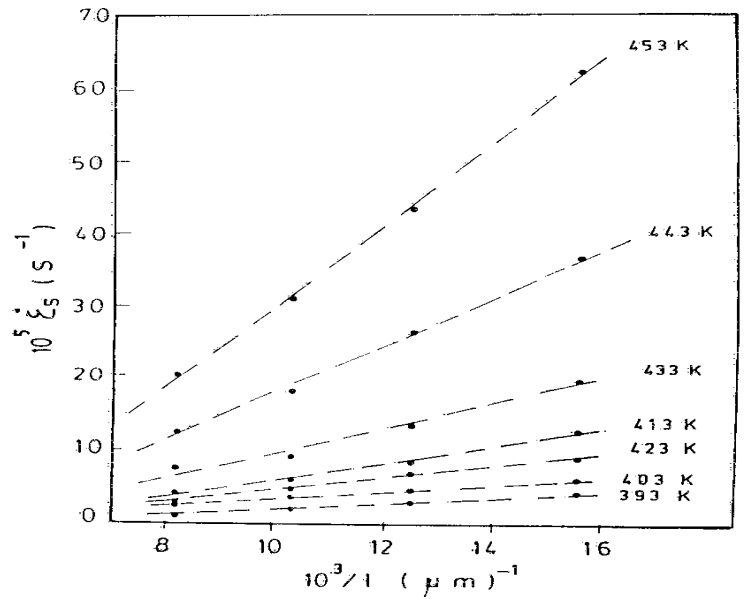



The effect of creep
temperature on the
microstructure parameters of Snrich phase of the $\mathrm{Sn}-1 \mathrm{wt} \% \mathrm{Zn}$ alloy samples rapidly quenched in water at room temperature (293K) after creep tests at all working temperatures are shown in Fig. 6. The precise lattice parameters $(\mathrm{a}, \mathrm{c})$, the residual lattice strain $\left(\Delta \mathrm{a} / \mathrm{a}_{\mathrm{o}}\right)$ and the ratio (c/a) are calculated from the $\mathrm{X}$ ray diffraction patterns of samples with grain diameter 64 $\mu \mathrm{m}$. From Fig. 6 it is clear that both a and $\left(\Delta \mathrm{a} / \mathrm{a}_{\mathrm{o}}\right)$ have minimum values, while $\mathrm{c}$ and $\mathrm{c} / \mathrm{a}$ have maxima at the transformation temperature.

\section{Discussion}

It has been established previously [2] that quenching technique prior to creep testing of Sn-1wt\% Zn alloy increases point defects and dislocation density. The rearrangement of these defects and dislocations leads to an inverted primary stage in which the strain rate

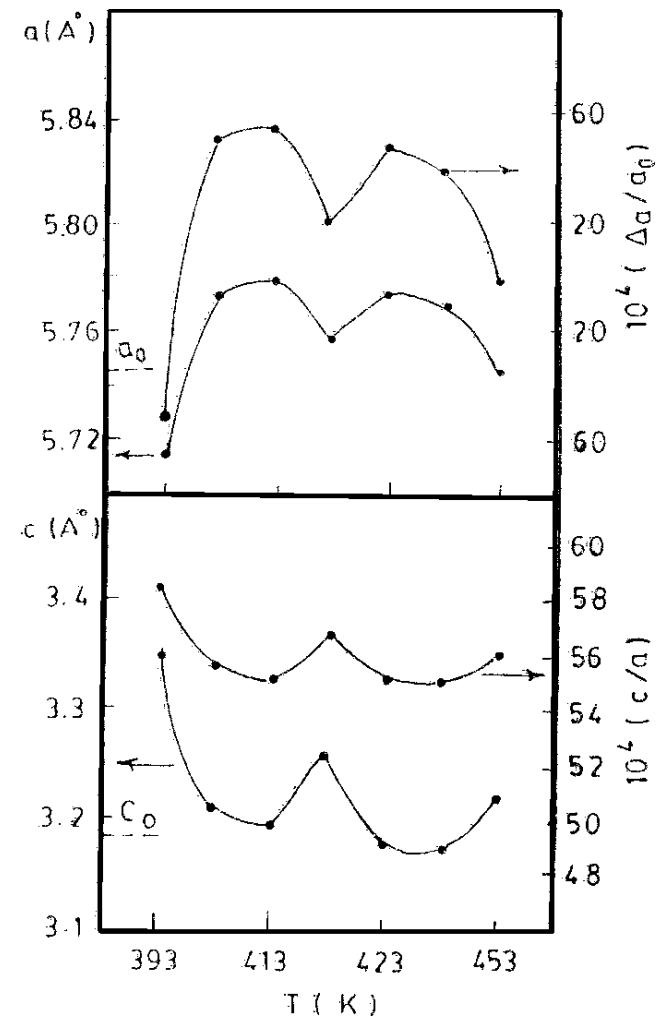

Fig. (6) Effect of working temperature on a) the lattice parameter a and the residual lattice strain $\left.\Delta \mathrm{a} / \mathrm{a}_{\mathrm{o}} ; \mathrm{b}\right)$ the lattice parameter $\mathrm{c}$ and the ratio c/a for the $\beta$-phase of Sn$1 \mathrm{wt} \% \mathrm{Zn}$ alloy of grain diameter $64 \mu \mathrm{m}$ gradually increases into the steady state region causing a disappearance of the primary creep stage in the isothermal creep curves [10] [see Fig. 1]. The strain values for all the investigated grain diameters show an anomalous behaviour in the vicinity of the transformation temperature $(423 \mathrm{~K})$, which is due to changes in the structural state of the examined alloy at this temperature [11].

The changes in the steady state creep rate $\left({ }^{\circ} \varepsilon_{\mathrm{s}}\right)$ of $\mathrm{Sn}-1 \mathrm{wt} \% \mathrm{Zn}$ alloy with both the working temperature and the grain size are shown in Fig. 2. These changes indicate that in the temperature range 393-413K the diffusion of $\mathrm{Zn}$ atoms to form $\alpha$-phase (Zn-rich phase) by ageing during creep tests enhances the creep process. This $\alpha$-phase starts to dissolve in the $\beta$-phase (Sn-rich phase) in the temperature range $413-423 \mathrm{~K}$ causing a decrease in ${ }^{\circ} \varepsilon_{\mathrm{s}}$. The decrease in ${ }^{\circ} \varepsilon_{\mathrm{s}}$ is due to the formation of Cottrell clouds which cause the capture of some mobile dislocations. The rapid increase in ${ }^{\circ} \varepsilon_{\mathrm{s}}$ in the high temperature range may 
be due to the viscous self-diffusion of Sn during the creep tests to reach the homogenized state of the alloy.

The observed decrease in ${ }^{\circ} \varepsilon_{\mathrm{s}}$ with increasing grain diameter at constant stress in the whole working temperature range could be explained on the basis that $\mathrm{Zn}$ in solid solution is homogeneously distributed on dislocations and has a strong influence on their thermal glide in the grain interior. As the grain size increases during the annealing process, the grain boundaries become more perfect and $\mathrm{Zn}$ atoms will no longer precipitate at these boundaries but remain in the grain interior. This eventually impedes the motion of the dislocations, consequently the steady state creep rate ${ }^{\circ} \varepsilon_{\mathrm{s}}$ decreases [12]. The linear relation between ${ }^{\circ} \varepsilon_{\mathrm{s}}$ and the reciprocal of the grain diameter at each working temperature is to some extent similar to these previously found $[7,13,14]$.

All the results between $\ln { }^{\circ} \varepsilon_{\mathrm{s}}$ and $1 / \mathrm{T}$ (Fig. 3) are in agreement with the equation of the steady state creep [15].

$$
\cdot \varepsilon_{\mathrm{s}}=\mathrm{A} \exp \left(-\mathrm{Q}_{\mathrm{s}} / \mathrm{KT}\right)
$$

The activation energy of the steady state creep $Q_{s}$ is slightly affected by the grain size of the test samples. In the low temperature range $\mathrm{Q}_{s}$ has an average value of $75.6 \pm 4.2 \mathrm{~kJ} / \mathrm{mol}$ which indicates that grain boundary sliding may be the dominant operating mechanism [16]. The average value of $\mathrm{Q}_{\mathrm{s}}$ increased to $103.1 \pm 3.8 \mathrm{~kJ} / \mathrm{mol}$ in the high temperature range. This refers to viscous self-diffusion of $\mathrm{Sn}(92-102 \mathrm{~kJ} / \mathrm{mol})[2,17]$ as the controlling mechanism in this temperature range.

The variations of the microstructural parameters (a,c, $\Delta \mathrm{a} / \mathrm{a}_{\mathrm{o}}$ and $\left.\mathrm{c} / \mathrm{a}\right)$ with the working temperature confirm that there is a transition point at $423 \mathrm{~K}$ for $\mathrm{Sn}-1 \mathrm{wt} \% \mathrm{Zn}$ alloy. These variations also emphasize the precipitation process of $\mathrm{Zn}$-rich phase in the temperature range (393-413K), the dissolution of $\mathrm{Zn}$ rich phase in the temperature range 413 to $423 \mathrm{~K}$ and the decreasing in the sum of internal lattice strains due to the thermally activated process at temperatures above $423 \mathrm{~K}$. The decreasing value of the residual lattice strain $(\Delta \mathrm{a} / \mathrm{ao})$ at $423 \mathrm{~K}$ can be attributed to the increase in the (partial) recovery of the internal stresses created in the process of formation of $\mathrm{Zn}$ precipitates and/or grain boundary sliding.

\section{References}

1. B.T.K. Barry and C.J. Thwattes, Tin and Its Alloys and Compounds, Chaps. 3, 4, Wiley, New York, (1983).

2. G.S. Al-Ganainy, phys. stat. sol. (a) 169, 217 (1998).

3. H. Mavoori, J. Chin, S. Vaynman, B. Moran, L. Keer, and M. Fine, J. of Electronic-Materials, 26(7), 783 (1997). 
4. M.S. Sakr, A.Z. Mohamed, A.A. El-Daly, A.M. Abdel-Daiem, and A.H. Bassyouni, Egypt. J. Sol., 13, 2, 34 (1990).

5. G.J. Davis, J.W. Edington, G.P. Culter, and K.A. Padmanabhan, J. Mater. Sci., 5, 1091 (1970).

6. G.V. Vladimirova, P. Lukacs, and G.A. Malygin, Phys. Met. Metallogr., 60(6), 161 (1985).

7. G. Saad, F. Abd El-Salam, and M.T. Mostafa; Surface Technology 22, 73 (1984).

8. S.B. Youssef, A. Fawzy, M. Sobhy, and G. Saad, Acta Phys. Slov. 43, 431 (1993).

9. M. Braunovic and C.W. Haworth, J. Appl. Phys. 40, 3459 (1969).

10. B. Wilshire and R.W. Evans, Creep Behaviour of Crystalline Solids, Pineridge press Ltd., Swansea (UK) 34 (1985).

11. M. Hansen, Constitution of Binary Alloys, McGraw-Hill Publ. Co., New York, 1217 (1958).

12. E.R. Parker, Proc. Amer. Soc. Testing Matter., 60, 849 (1960).

13. N.J. Petch, J. Iron Steel Inst., 174, 25 (1953).

14. E. O. Hall, Proc . Phys. Soc., 64, 747 (1951).

15. R.W.K. Honeycombe, The Plastic Deformation of Metals, Edward Arnold, 369 (1984).

16. L. Rotherham, A. Smith, and G. Greenough, J. Inst. Metals 79, 439 (1951).

17. F. Garofalo, Fundamentals of Creep and Creep-Rupture in Metals, The MacMilan Co., New York, 1965 (p. 85). 